\title{
Synthesis and molecular and electronic structure of an unusual paramagnetic borohydride complex $\mathrm{Mo}(\mathrm{NAr})_{2}\left(\mathrm{PMe}_{3}\right)_{2}\left(\eta^{2}-\mathrm{BH}_{4}\right)$
}

Andrey Y. Khalimon, ${ }^{a}$ Jason P. Holland, ${ }^{b}$ Radoslaw M. Kowalczyk, ${ }^{c}$ Eric J. L. McInnes, ${ }^{c}$ Jennifer C. Green, ${ }^{b}$ Philip Mountford, ${ }^{b}$ and Georgii I.

Nikonov*,a

\section{SUPPORTING INFORMATION}

Table S1. Cartesian coordinates (in atomic units) of the gas phase DFT optimised structure of $\mathrm{Mo}\left(\mathrm{NAr}^{\prime}\right)_{2}\left(\mathrm{PMe}_{3}\right)_{2}\left(\eta^{2}-\mathrm{BH}_{4}\right)(\mathbf{I})$.

$\begin{array}{ll}\text { Atomic number } & x \\ 42 & 1.624872 \\ 15 & 0.672815 \\ 15 & 2.283327 \\ 7 & 1.153684 \\ 6 & 1.879534 \\ 7 & 3.282202 \\ 6 & 0.892695 \\ 6 & 4.533053 \\ 6 & 3.777337 \\ 6 & 5.535674 \\ 6 & 6.157402 \\ 5 & 0.050911 \\ 6 & 5.16826 \\ 6 & 3.19143 \\ 6 & 4.850255 \\ 6 & -0.3893 \\ 6 & 7.146576 \\ 6 & 6.824958 \\ 6 & 1.244514 \\ 6 & -1.12869 \\ 6 & -1.43428 \\ 6 & 2.789279 \\ 6 & 0.983363 \\ 1 & 3.063288 \\ 6 & 1.587553 \\ 6 & 1.018555 \\ 6 & 3.680704 \\ 1 & 4.190147 \\ 6 & 0.344871 \\ 6 & -0.63121 \\ 1 & 3.087076 \\ 1 & 3.903408 \\ 1 & -1.73755 \\ 1 & -2.32751 \\ 1 & 4.602828 \\ 1 & 6.057915 \\ 1 & -0.19326 \\ & \\ 6 & \end{array}$

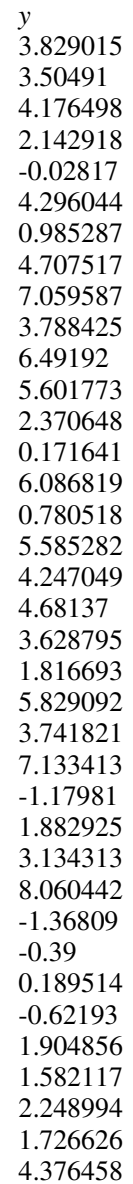
2.084562 $-0.16749$

4.441842

2.605064

3.338734

1.521039

3.227171

1.253151

1.686571

0.856457

1.173244

2.476352

0.640896

2.68342

1.375427

3.810038

0.821217

0.65188

$-1.41758$

$-0.25609$

3.643257

4.976891

5.617565

0.846407

4.046905

$-0.89842$

4.932076

1.879327

4.634288

4.505772

1.583417

2.953481

2.583794

4.240258

$-0.30206$

0.585531

2.665863 


$\begin{array}{llll}1 & 1.166719 & 5.746654 & 1.901704 \\ 1 & -0.79743 & 6.010469 & 1.701915 \\ 1 & 0.065489 & 6.181165 & 3.549027 \\ 1 & 3.167464 & 6.744975 & 2.548476 \\ 1 & 6.401214 & 7.553849 & 1.288221 \\ 1 & 4.498283 & 2.010514 & 1.437277 \\ 1 & 3.624855 & 1.150654 & 2.952848 \\ 1 & 8.173314 & 5.926492 & 0.668746 \\ 1 & 7.597976 & 3.530312 & 0.353449 \\ 1 & 2.345598 & 4.643742 & -1.46565 \\ 1 & 0.950018 & 5.697044 & -1.10726 \\ 1 & 0.815356 & 4.457917 & -2.40899 \\ 1 & -1.57014 & 2.846173 & 0.38334 \\ 1 & -1.42447 & 4.609305 & 0.155673 \\ 1 & -1.49464 & 3.515923 & -1.29046 \\ 1 & -1.06372 & 2.818298 & 3.921401 \\ 1 & 3.719034 & 6.116026 & 4.458327 \\ 1 & 2.958491 & 5.847105 & 6.06665 \\ 1 & 1.992011 & 6.543127 & 4.709388 \\ 1 & 0.680296 & 2.692995 & 5.445515 \\ 1 & 1.332601 & 3.860862 & 6.65712 \\ 1 & 0.117419 & 4.400532 & 5.435992 \\ 1 & 2.359474 & -1.95219 & 4.13657 \\ 1 & 0.65332 & 1.107891 & -0.20393 \\ 1 & 2.109029 & 1.76022 & -1.00284 \\ 1 & 0.533934 & 1.765109 & -1.88251 \\ 1 & 3.383949 & 2.076206 & 4.830579 \\ 1 & 3.986003 & 3.330612 & 5.973766 \\ 1 & 4.527196 & 3.333583 & 4.252561 \\ 1 & 0.134072 & -2.28431 & 5.190828 \\ 1 & -1.61808 & -0.53744 & 4.958328\end{array}$

Table S2. Cartesian coordinates (in atomic units) of the gas phase DFT optimised structure of $\mathrm{Mo}\left(\mathrm{NAr}^{\prime}\right)_{2}\left(\mathrm{PMe}_{3}\right)_{2}\left(\eta^{2}-\mathrm{BH}_{4}\right)(\mathbf{I I})\left(\mathrm{BH}_{4}\right.$ unit rotated by $90^{\circ}$ relative to that in $\left.\mathbf{I}\right)$

$\begin{array}{ll}\text { Atomic number } & x \\ 42 & -0.00328 \\ 15 & 2.549885 \\ 15 & -2.56291 \\ 7 & -0.04214 \\ 6 & -0.09407 \\ 7 & -0.07696 \\ 6 & -0.07708 \\ 6 & -0.20636 \\ 6 & -0.11365 \\ 6 & -0.30428 \\ 6 & -0.39846 \\ 5 & -0.2164 \\ 6 & -0.24788 \\ 6 & -0.06526 \\ 6 & -0.24424 \\ 6 & -0.09343 \\ 6 & -0.50367 \\ 6 & -0.45243 \\ 6 & 3.404916 \\ 6 & 3.319778 \\ 6 & -0.05996 \\ 6 & -3.40353 \\ 6 & -3.31818 \\ 1 & 0.860575 \\ 6 & -0.14222 \\ 6 & 3.312917 \\ 6 & -3.36782 \\ 1 & -0.21649 \\ 6 & -0.16796 \\ 6 & -0.14239 \\ 1 & 0.826941 \\ 1 & -0.06995\end{array}$

$\begin{array}{ll}y & z \\ 0.041574 & -0.03 \\ 0.038164 & -0.10999 \\ 0.168707 & 0.050774 \\ 1.156987 & -1.49143 \\ 1.294339 & -3.93216 \\ -1.78657 & 0.116551 \\ 1.898287 & -2.6332 \\ -3.14016 & 0.214558 \\ -2.87351 & 2.748881 \\ -3.97773 & -0.94279 \\ -5.11695 & 1.62985 \\ 1.368785 & 2.473379 \\ -3.37672 & -2.31943 \\ -0.2017 & -4.07096 \\ -3.73355 & 1.521809 \\ 3.330886 & -2.52084 \\ -5.9319 & 0.498028 \\ -5.35641 & -0.77439 \\ -0.55968 & 1.412484 \\ 1.688067 & -0.39882 \\ 3.983966 & -1.16504 \\ -0.76016 & 1.404032 \\ 1.848029 & 0.144418 \\ -2.36264 & 2.778838 \\ 2.113673 & -5.06238 \\ -1.00598 & -1.43154 \\ -0.52904 & -1.46297 \\ -3.47628 & 3.660296 \\ 3.506669 & -4.95081 \\ 4.098503 & -3.68348 \\ -0.63346 & -3.59332 \\ -0.50014 & -5.12724\end{array}$




$\begin{array}{llll}1 & 0.836006 & 3.689556 & -0.59943 \\ 1 & -0.06979 & 5.07743 & -1.25817 \\ 1 & 0.666234 & -2.78209 & -2.46056 \\ 1 & -0.27901 & -4.15646 & -3.09147 \\ 1 & 0.534332 & 0.870313 & 1.513832 \\ 1 & -1.41632 & 1.274686 & 2.330914 \\ 1 & 0.205996 & 0.707031 & 3.403107 \\ 1 & 0.174132 & 2.52097 & 2.445304 \\ 1 & -0.86516 & -2.07199 & 2.769537 \\ 1 & -0.43505 & -5.56575 & 2.624951 \\ 1 & -1.08806 & -2.68766 & -2.49266 \\ 1 & -0.92846 & -0.66878 & -3.57436 \\ 1 & -0.62276 & -7.01013 & 0.607563 \\ 1 & -0.52769 & -5.99114 & -1.66044 \\ 1 & 3.122436 & -1.60559 & 1.595525 \\ 1 & 3.072997 & 0.04384 & 2.268524 \\ 1 & 4.497703 & -0.49015 & 1.308788 \\ 1 & 2.932777 & 2.10585 & -1.33858 \\ 1 & 3.041867 & 2.361215 & 0.423674 \\ 1 & 4.415347 & 1.608383 & -0.45331 \\ 1 & -0.91376 & 3.678011 & -0.54401 \\ 1 & -3.11311 & -1.81863 & 1.345734 \\ 1 & -4.49693 & -0.67566 & 1.318564 \\ 1 & -3.07422 & -0.35258 & 2.369118 \\ 1 & -3.01803 & 2.423266 & -0.74244 \\ 1 & -4.4155 & 1.77936 & 0.179003 \\ 1 & -2.94701 & 2.355045 & 1.044762 \\ 1 & -0.15986 & 1.647905 & -6.05059 \\ 1 & 2.97913 & -0.64804 & -2.41502 \\ 1 & 2.982303 & -2.04573 & -1.30327 \\ 1 & 4.411035 & -0.96326 & -1.38488 \\ 1 & -3.01154 & 0.018415 & -2.34656 \\ 1 & -4.46309 & -0.44569 & -1.40276 \\ 1 & -3.09257 & -1.58777 & -5.56502 \\ 1 & -0.20766 & -3.5598 \\ 1 & -0.1592 & 5.1868596 & \\ & & & \end{array}$

Table S3. Cartesian coordinates (in atomic units) of the gas phase DFT optimised structure of $\left[\mathrm{Mo}\left(\mathrm{NAr}^{\prime}\right)_{2}\left(\mathrm{PMe}_{3}\right)_{2}\right]^{+}(\mathbf{V})$

$\begin{array}{llll}\text { Atomic number } & x & y & z \\ 42 & 1.765452 & 3.694078 & 2.054816 \\ 15 & 0.48956 & 3.701796 & -0.06519 \\ 15 & 2.059487 & 4.326097 & 4.412275 \\ 7 & 1.237477 & 2.082654 & 2.64146 \\ 6 & 1.938822 & -0.09475 & 3.36294 \\ 7 & 3.364124 & 4.299049 & 1.503439 \\ 6 & 0.955242 & 0.910972 & 3.249667 \\ 6 & 4.632886 & 4.69109 & 1.23888 \\ 6 & 3.867564 & 7.052861 & 1.642726 \\ 6 & 5.624737 & 3.758708 & 0.866849 \\ 6 & 6.235568 & 6.477968 & 1.101788 \\ 6 & 5.270938 & 2.331477 & 0.706928 \\ 6 & 3.26129 & 0.10778 & 2.732446 \\ 6 & 4.933611 & 6.071956 & 1.333102 \\ 6 & -0.34374 & 0.726195 & 3.783223 \\ 6 & 7.217599 & 5.563955 & 0.756531 \\ 6 & 6.907893 & 4.2202 & 0.630547 \\ 6 & 1.033806 & 4.849887 & -1.34523 \\ 6 & -1.31315 & 3.713273 & -0.15102 \\ 6 & -1.39146 & 1.755833 & 3.58004 \\ 6 & 2.595177 & 5.961317 & 4.954503 \\ 6 & 0.763694 & 3.857862 & 5.573864 \\ 1 & 3.151007 & 7.1286 & 0.805819 \\ 6 & 1.61985 & -1.25257 & 4.04934 \\ 6 & 0.910267 & 2.077528 & -0.75343 \\ 6 & 3.441109 & 3.267078 & 4.913282\end{array}$


4.604368

$-0.44829$

4.464713

0.27039

1.644823

$-0.75395$

2.896157

2.523703

4.193525

1.546908
2.185871

$-0.16723$

1.711644

0.559892

6.753155

2.517393

7.541195

1.187337

1.576897

1.012356

3.123773

5.906725

0.575234

0.340708

4.81592

5.878757

$-1.40801$

$-1.10293$

4.558284

2.957872

$-2.31751$

0.541592

0.128194

3.46843

2.768685

$-1.18029$

3.808995

6.228062

4.445444

5.929809

6.042962

4.73481

5.399307

6.604056

5.448521

4.144659

$-0.07577$

$-0.82438$

$-1.75589$

4.810862

5.963319

4.26154

5.146943

4.891294 